\title{
Miscounseling in Monopolistic Competition: A Case for Regulation
}

\author{
Annette Hofmann ${ }^{1} \&$ Salem Saljanin ${ }^{2}$ \\ ${ }^{1}$ Institute for Risk and Insurance, University of Hamburg, Hamburg, Germany \\ ${ }^{2}$ University of Hamburg, Hamburg, Germany \\ Correspondence: Salem Saljanin, Institute for Risk and Insurance, University of Hamburg, Hamburg, Germany. \\ E-mail: saljanin@hzv-uhh.de. Tel: 49-40-428-384-043
}

Received: October 17, 2012 Accepted: January 7, 2013 Online Published: February 18, 2013

doi:10.5539/res.v5n1p19 URL: http://dx.doi.org/10.5539/res.v5n1p19

\begin{abstract}
We analyze the impact of (possibly) fraudulent independent experts in a market for credence goods characterized by monopolistic competition. This setting applies to various industries such as repair markets, health care markets or financial services markets where consumers are usually uninformed about which product best fits their individual needs. Some consumers prefer to use an expert. We analyze market outcomes with honest and fraudulent experts, whereby honesty may require side payments from firms to experts. Rigorous regulation of the relationship between firms and experts may be essential in order to make these markets operate more efficiently.
\end{abstract}

Keywords: imperfect markets, miscounseling, monopolistic competition, collusion

\section{Introduction}

Miscounseling is a phenomenon of great relevance. A rather spectacular case occurred in 2004 when New York Attorney General Eliot Spitzer sued Marsh \& McLennan, the largest insurance broker in the world, for collusion with major insurance companies. In the civil complaint filed in State Superior Court in Manhattan, Spitzer alleges that Marsh steered unsuspecting clients to insurers with whom it had lucrative payoff agreements, and that the firm solicited rigged bids for insurance contracts. For a long time in the United States, insurance brokers have received high payments from insurance companies they ostensibly evaluate objectively on behalf of customers who pay fees in good faith in order to have their coverage arranged. Insurance brokers insist that the payments from insurers-often referred to as contingent commissions or placement-service agreements-do not influence their advice in any way, and that they regard the money as an ex-post reward for a job well done. Since the late 1990s, brokers have been disclosing these payments in general terms (Spitzer, 2004). In 2005, Marsh \& McLennan has agreed to pay $\$ 850$ million to settle civil fraud allegations that it steered business to insurance companies in exchange for payments. Fitzpatrick (2006) offers a detailed discussion of the case.

Economic models generally assume that consumers know which goods or services they need. Many goods, however, exhibit characteristics that cannot be revealed by inspection or ordinary use. These goods are known as credence goods. In such cases, consumers often have to rely on an expert's advice to assess their actual needs. This creates the possibility of miscounseling. There are many examples of situations were consumers face the problem of buying goods or services not necessarily suitable to them. Common examples include all sorts of repair markets, health care markets as well as legal and financial services markets. In view of the financial crisis of 2008, a very important example are mortgage brokers. Many observers of the ongoing financial crisis assign them a great deal of responsibility.

Obviously, there is a need for means, besides legal restraints, to fight miscounseling. One possibility is to establish reputation. This approach, however, requires repeated interaction and a comparatively high level of information of all parties involved. Another possibility is some consumer protection institution, which again would produce a bunch of new incentive problems, especially enforcement problems. The most straightforward way to ensure honest counseling seems to separate counseling and purchase. But that may not be enough.

The main purpose of this paper is to analyze the consequences of fraudulent independent experts in a model of monopolistic competition. We use the well-known circular product space introduced by Salop (1979). In the original Salop model, all consumers know their position in the product space. We examine market and welfare effects of relaxing this crucial assumption, and incorporate uninformed consumers and fraudulent independent experts into this framework. The contribution of the paper is threefold. First, we study the question of how much 
miscounseling should be expected in a market equilibrium featuring these characteristics. Second, we analyze agents' optimal pricing strategies and product varieties offered under miscounseling. Third, we analyze the impact of side payments - payments to experts in order to prevent them from business stealing. We find that miscounseling will not happen in equilibrium given side payments. The existence of side payments leads to fewer firms and higher prices in market equilibrium compared to the standard full-information Salop equilibrium.

The paper is organized as follows. Section 2 discusses related literature. The model is presented in section 3 . Side payments to brokers are considered in more detail in section 4 . Section 5 studies the brokers' behavior. A short summary follows.

\section{Literature Review}

There are several strands of literature we build upon. On the one side, our model is loosely related to the literature on credence goods. This literature is surveyed by Dulleck and Kerschbamer (2006). Contrary to this literature, however, we accentuate the consequences of bribery in a model of monopolistic competition which, to the best of our knowledge, has not previously been used to answer the questions we pose in this paper. The monopolistic-competition assumption is convenient since product differentiation of credence goods is a common phenomenon. This approach offers the possibility to study the consequences of miscounseling on the number of offered brands in equilibrium. A better understanding of incentive problems and miscounseling may clearly be very helpful in designing better public and regulation policy. On the other side, there is a large literature related to financial intermediation. There are two main strands in this literature that are related to our model. The first is concerned with capital markets in general while the second is related particularly to insurance markets. In the first strand of literature, various authors analyze the benefits of delegating some informational task to an intermediary who is presumed to have some transaction cost advantage over consumers.

There is significant literature (that cannot be reviewed here) dealing with informational asymmetries in banks and financial services markets, particularly commercial bank markets. Those markets are studied, for instance, by Chan (1983), Leland and Pyle (1977), Campbell and Kracaw (1982), Diamond (1984) and Williamson (1987) as well as Allen and Santomero (1997). Most authors stress the role of transaction costs. For example, fixed costs of asset evaluation imply that intermediaries have an advantage over individuals because they allow such costs to be shared. In a similar way, trading costs imply that intermediaries can more easily be diversified than individuals. In the second strand of literature on financial intermediation, authors explicitly address insurance markets. Brokers as search agents whose function is to match trading partners in insurance markets are studied by Rubinstein and Wolinsky (1987). The authors analyze time-consuming negotiations between buyers, sellers and middlemen. Posey and Yavas (1995) as well as Posey and Tennyson (1998) study search cost models while Cosimano (1996) looks at a monopolist intermediary who lowers the probability of an unsuccessful trade. Seog (1999) offers a dynamic model and focuses on price search. Intermediation is found to solve adverse selection problems in insurance markets as illustrated by Biglaiser (1993) and Cummins and Doherty (2006). Among all these studies, our paper is most related to Gravelle (1994). Gravelle is, however, not concerned with matching. In his setting, products are homogeneous and consumers differ in their willingness to pay for insurance coverage which is determined by some unknown random variable. This variable is only observed by brokers. Thus the brokers' main service is to advise consumers on whether they should purchase insurance or not. In contrast to Gravelle, our focus here is on corrupt independent experts. We allow for product differentiation and product-specific mismatching which allows for different degrees of consumer miscounseling.

Inderst and Ottaviani (2009) analyze the optimal compensation structure for a direct marketing agent who must be incentivized to sell and, simultaneously, not to miscounsel. They are concerned with the internal agency problem and do not address market outcomes as a result of competition among different firms and independent brokers, which is the main focus of this paper. Hoffmann and Inderst (2011) analyze how a seller optimally chooses the costly quality of pre-sale information, next to the price of information and the product price. They are, however, also not concerned with the effects of miscounseling on the market outcomes and performance. Inderst and Ottaviani (2010) construct a model to analyze competition through commissions. They, however, restrict their analysis to a Hotelling framework with only two firms. Finally, Inderst (2011) and Inderst and Ottaviani (2011) discuss reasons why markets with advice may fail, and explore various policy options.

\section{The Model}

\subsection{The Assumptions}

We adopt a model of product differentiation based on Salop (1979). Consumers are uniformly distributed on a circle of unit circumference. We assume that each firm $i=1,2, \ldots, n$ has constant marginal cost $c>0$, each of 
which decides whether to enter the market and then selects a symmetric location in the unit circle. All firms have uniform fixed $\operatorname{cost} f>0$. Consumers have linear unit transport cost proportional to the distance to firms, and buy one unit of the good from the firm for which price plus travel cost is lowest. Transport cost is due to the "mismatch between consumers' individual preferences and offered product varieties. The model is a three-stage game.

- Stage 1: All firms (simultaneously) decide whether to enter the market; firms entering the market are equidistantly located on the circle.

- Stage 2: Brokers decide upon their fees.

- Stage 3: Having observed the locations selected and the brokers' fees, each firm simultaneously offers a price and decides about how to handle the business with the brokers, i.e., business stealing or side payments strategy (which we specify below).

The solution concept is subgame-perfect equilibrium. We assume that consumers do not know their position on the circle ex ante. Consider the individual decision problem of an uninformed consumer who decides upon becoming an informed consumer: In case he becomes informed, he can choose between the nearest firms located in the product space left and right to his position on the circle. Without loss of generality, we denote these two firms by $i$ and $i+1$, respectively. An informed consumer located at $x \in(0,1 / n)$ faces mismatch $x$ from purchasing a product from firm $i$ (and respectively $1 / n-x$ when he purchases at $i+1$ ), so his mismatch ranges from 0 to $1 /(2 n)$ implying an expected mismatch of $1 /(4 n)$. An uninformed consumer's mismatch is between 0 and $1 / 2$, which implies an expected mismatch of 1/4. The consumer's situation is illustrated in Figure 1.

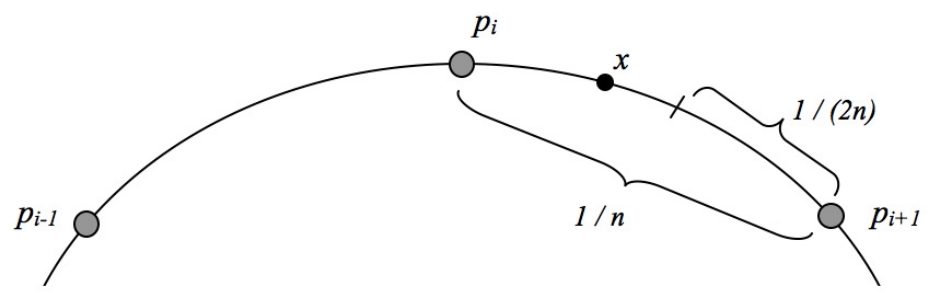

Figure 1. Situation of an informed consumer

Since consumers do not know their position on the Salop circle, they base their decision to become informed about the adequate product variety on the advantage of being informed versus the cost of becoming informed. A consumer $l \in[0,1)$ may engage in costly search for her best-fitting variety. Suppose consumers' search costs $\theta_{l} \in[0, \infty)$ is governed by some cumulative distribution function $F\left(\theta_{l}\right)$. It is of crucial importance to note that search costs may also include expected personal cost resulting from miscounseling, that is, each consumer anticipates that she may be miscounseled. Given consumers are rational, searching for an optimal product variety takes place if the expected reduction in transport cost is greater than individual search cost, hence if

$$
\theta_{l}+\frac{1}{4 n} \leq \frac{1}{4}
$$

As a consequence, there is an indifferent consumer with search cost $\bar{\theta}$, where

$$
\bar{\theta}:=\frac{n-1}{4 n} .
$$

such that a share of $F(\bar{\theta})$ consumers becomes informed while $1-F(\bar{\theta})$ prefer to stay uninformed. Uninformed consumers rationally follow the "principle of insufficient reason" and purchase at the cheapest provider. ${ }^{1}$ Therefore, firms engage in local competition for informed consumers and in Bertrand competition for uninformed consumers. Given this type of competitive environment, as shown by [?] using Hotelling's street, no pure-strategy equilibrium exists but only a mixed-strategy equilibrium where prices are lower than in the full-information pure-strategy case. In the face of costly product differentiation, it seems forceful that providers seek to inform every consumer on the "advantage" of their own variety. Since advertising alone is hardly efficient in matters of complex products, engaging intermediaries, who act as information brokers, is common practice. 
Suppose there is a market of $m>1$ identical information brokers advising a consumer about his individual position in the circle and hence of his best-fitting product variety against payment of some fee $k_{j}>0$, where $j=1,2, \ldots, m$. The number of brokers is assumed exogenous for two reasons. First, we are mainly concerned with the consequences of miscounseling on the firms. Second, government regulations often restrict the number of brokers. For example, the requirement for licenses and permits may limit the number of brokers. ${ }^{2}$ Given that a representative broker $j$ operates along the whole market $[0,1)$, she engages in pairwise Bertrand competition with $m-1$ brokers at any location $x \in[0,1)$. If consumers can observe all $k_{j}$, the information market becomes competitive, so $k_{j}=k$ for all $j$, where $\mathrm{k}$ is marginal cost of advising a consumer. Now, the decision problem of an uninformed consumer upon becoming informed is threefold. Consumers with $\theta<\min \{k, \bar{\theta}\}$ engage in individual search, while consumers with $\theta \geq \min \{k, \bar{\theta}\}$ consult an information intermediary or stay uninformed depending on the fee $k$. If the brokers' fee is above $\theta$, those consumers prefer to stay uninformed since the cost of information is above its expected benefit. Then there is no demand for the brokers' service. If, however, $k \leq \theta$ holds, all consumers become informed about product varieties. Making the reasonable assumption that this inequality indeed holds and hence the brokers' fee is below the expected benefit of information, there exists a broker market in which providers engage in purely spatial competition. Since brokers are identical, we further assume that consumers' demand for information distributes symmetrically among all $m$ intermediaries for any location $x \in[0,1)$.

Given that all consumers undertake an informed purchase decision, we may derive firm $i$ 's demand. Suppose that $x_{i}$ is the location of a consumer who is indifferent between varieties offered at $i$ and $i+1$, that is

$$
\bar{x}_{i}:=\frac{p_{i+1}-p_{i}+\frac{1}{n}}{2} \quad i=1,2, \ldots, n .
$$

As a point of reference, assume that brokers are honest. This means brokers always give their customers the right advice about their actual position on the unit circle. Then, as in the standard full-information setting, firm $i$ 's demand is given by

$$
D_{i}\left(p_{i-1}, p_{i}, p_{i+1}\right)=\frac{p_{i+1}+p_{i-1}-2 p_{i}+2 / n}{2} .
$$

Firm $i$ seeks to maximize $\Pi_{i}\left(p_{i-1}, p_{i}, p_{*}\right)=\left(p_{i}-c\right) D_{i}-f$. Differentiating with respect to $p_{i}$ and setting $p_{i}=p_{i-1}=p_{i+1}=p$ yields $p \stackrel{*}{=} c+1 / n$, which leads to $D_{i}=D_{i-1}=D_{i+1}=D=1 / n$ implying $\Pi(n)_{i}=1 / n^{2}-f$. We may then determine the equilibrium number of firms from the zero-profit condition for existing firms, $(p-c) / n-f=0$, which implies the equilibrium number of firms

$n_{0}=\sqrt{1 / f}$ and equilibrium market price $p_{0}=c+\sqrt{f}$. This equilibrium seems, however, unrealistic from the brokers' view. Why should they earn zero profits and act honestly? Therefore, we assume in the following that brokers are corrupt and miscounsel consumers in favor of a firm against some price.

\subsection{Market Equilibrium}

As discussed above, many sales practices observed in markets for complex products sail fairly close to the wind. Hence, one is probably concerned to what degree competitors might dishonestly play on informational asymmetries leaving consumers ripped off? Given that products are complex and some consumers require the service of information brokers, a representative provider may bribe brokers into advising consumers to purchase its own variety instead of some better-fitting competitor's. If this is a rational strategy, any broker will encounter such fraudulent attempts. It is not unrealistic to assume that when a broker participates in such collusive agreements with firms, miscounseling consumers is associated with additional efforts. This is because brokers need to convince consumers about their best-fitting product variety which becomes more difficult the less a product actually fits a consumer's preferences. We assume that brokers try to convince consumers to be "located at the respective indifference border $x_{i}$ instead of their "real position. For the sake of simplicity, suppose that the cost of miscounseling increases linearly with the degree of miscounseling, i.e. the distance $\left|x-x_{i}\right|$. These costs may arise for various reasons. First, there may be penalties if miscounseling is detected. Second, there may be costs of manipulating information. Third, many people have an intrinsic aversion to lying.

Interestingly, though purely competitive for consumers' information demand, brokers enjoy market power in their miscounseling activities. Since consumers' demand for information from brokers is given by $1-F(k)$ at any $x \in[0,1)$ and distributes symmetrically among $\mathrm{m}$ brokers, every one is left with control on $v_{x}(m, k):=(1-F(k)) / m$ of demand density. In respect of miscounseling cost-which is increasing linearly in the 
degree of miscounseling - consumers who are located closely to an indifferent consumer $\bar{x}_{i}$ are more attractive victims. Every broker $j$ holds control on a share $1 / m$ of potential victims. Thus, if firms refuse a broker's miscounseling fee, they cannot revert to a different broker who miscounsels potential victims of other firms. As a consequence, any broker acts as a monopolist offering miscounseled victims to firms. The miscounseling market can therefore be seen as quasi monopolistically competitive.

We do not specify the brokers' behavior in more detail here, but instead suppose only that brokers charge some markup $\sigma>0$ on their cost of miscounseling. ${ }^{3}$ The brokers' behavior is studied later in section 5 .

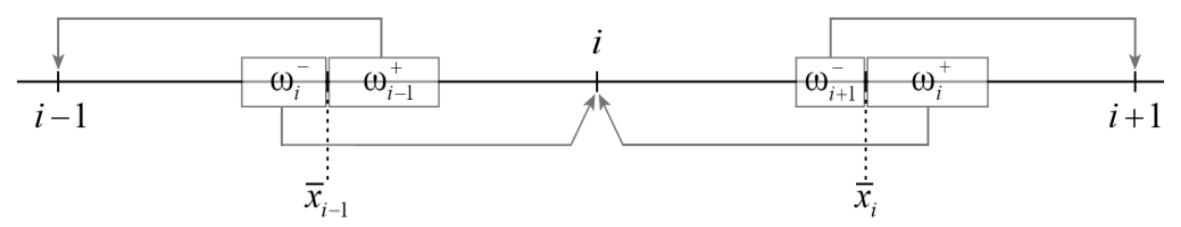

Figure 2. Consumers near the indifference border fall victim to miscounseling

A representative firm $i$ may decide to attract an upstream $\omega_{i}^{+}$and downstream $\omega_{i}^{-}$amount of consumers from its adjacent competitors through miscounseling (see Figure 2). Mathematically, taking into account that merely a fraction $1-F(k)=: \lambda_{k}$ of consumers even asks for informational advice from a broker, brokers' miscounseling intervals are expanded by a factor $1 / \lambda_{k}$ in order to satisfy a provider's request for business stealing. In order to capture the market share $\left(\omega_{i}^{+}+\omega_{i}^{-}\right)$, an upstream $\left[\bar{x}_{i}, x_{i}+\omega_{i}^{+} / \lambda_{k}\right]$ and downstream $\left[\bar{x}_{i-1}-\omega_{i}^{-} / \lambda_{k}, \bar{x}_{i-1}\right]$ interval of miscounseling is required. Providers' cost of business stealing are given by

$$
\mu\left(\omega_{i}^{+}, \omega_{i}^{-}\right)=\int_{\bar{x}_{i}}^{\bar{x}_{i}+\omega_{i}^{+} / \lambda_{k}}(1+\sigma)\left(x-\bar{x}_{i}\right) d x+\int_{\bar{x}_{i-1}}^{\bar{x}_{i-1}-\omega_{i}^{-} / \lambda_{k}}(1+\sigma)\left(x-\bar{x}_{i-1}\right) d x
$$

which reduces to

$$
\mu\left(\omega_{i}^{+}, \omega_{i}^{-}\right)=\frac{(1+\sigma)\left(\left[\omega_{i}^{+}\right]^{2}+\left[\omega_{i}^{-}\right]^{2}\right)}{2 \lambda_{k}^{2}} .
$$

Given the locally competitive environment $P_{i}:=\left(p_{i-1}, p_{i}, p_{i+1}\right) \in[0, \infty)^{3} \quad$ and $\Omega_{i}:=\left(\omega_{i}^{+}, \omega_{i}^{-}, \omega_{i-1}^{+}, \omega_{i+1}^{-}\right) \in[0,1 / 2)^{4}$, demand of a representative firm is given by

$$
D_{i}\left(P_{i}, \Omega_{i}\right)=\frac{p_{i+1}+p_{i-1}-2 p_{i}+\frac{2}{n}}{2}+\omega_{i}^{+}+\omega_{i}^{-}-\left(\omega_{i-1}^{+}+\omega_{i+1}^{-}\right)
$$

which implies the following profit maximization problem for firm $i$ :

$$
\max _{\left\{p_{i}, \omega_{i}^{+}, \omega_{i}^{-}\right\}} \Pi_{i}\left(P_{i}, \Omega_{i}\right)=\left(p_{i}-c\right) D_{i}\left(P_{i}, \Omega_{i}\right)-\mu\left(\omega_{i}^{+}, \omega_{i}^{-}\right)-f .
$$

Definition 1 The set $\left\{n^{b s}, p^{b s}, \omega^{b s}, \sigma^{b s}\right\}$ describes a symmetric business stealing equilibrium (SBSE) if

1. Firms: Each firm acts as a monopoly on its brand, that is, given the demand for brand $i$ (7) and the miscounseling parameters $\omega_{i}^{+}$and $\omega_{i}^{-}$, eachfirm $i$ chooses $p_{i}, \omega_{i}^{+}$, and $\omega_{i}^{-}$to

$$
\max _{\left\{p_{i}, \omega_{i}^{+}, \omega_{i}^{-}\right\}} \Pi_{i}\left(P_{i}, \Omega_{i}\right)=\left(p_{i}-c\right) D_{i}\left(P_{i}, \Omega_{i}\right)-\mu\left(\omega_{i}^{+}, \omega_{i}^{-}\right)-f
$$


2. Free entry: Free entry of firms until every firms earns zero profits, $\Pi_{i}=0 \forall i$

3. Brokers: Each broker j chooses the level of markup $\sigma_{j}$ on their miscounseling cost to

$$
\max _{\sigma_{j}} \frac{n \sigma_{j} \omega^{2}\left(\sigma_{j}\right)}{m \lambda_{k}^{2}}
$$

The associated first-order conditions for (8) are:

$$
\begin{gathered}
\frac{p_{i-1}+p_{i+1}-4 p_{i}}{2}+\omega_{i}^{+}+\omega_{i}^{-}-\left(\omega_{i-1}^{+}+\omega_{i+1}^{-}\right)=-\frac{1+n c}{n} \\
\lambda_{k}^{2}\left(p_{i}-c\right)=(1+\sigma) \omega_{i}^{+} \\
\lambda_{k}^{2}\left(p_{i}-c\right)=(1+\sigma) \omega_{i}^{-} .
\end{gathered}
$$

Note that from the adjacent competitors' first-order conditions, we know $\omega_{i-1}^{+}$and $\omega_{i+1}^{-}$. Inserting $\omega_{i}^{+}$ and $\omega_{i}^{-}$gives

$$
\underbrace{-\frac{2\left(1+\sigma-\lambda_{k}^{2}\right)}{(1+\sigma)}}_{=: \phi} p_{i}+\underbrace{\frac{1+\sigma-2 \lambda_{k}^{2}}{2(1+\sigma)}}_{=: \psi}\left(p_{i-1}+p_{i+1}\right)=-\frac{1+n c}{n} .
$$

As there are $i=1,2, \ldots, n$ firms in the market, we have a n-dimensional algebraic systems of first-order conditions:

$$
\left\{\phi p_{i}+\psi\left(p_{n+1-1[n]}+p_{i+1[n]}\right)=b\right\}_{i=1,2, \ldots, n} .
$$

If this system of equations is written in its matrix representation

$$
\mathbf{A} \cdot \mathbf{p}=\mathbf{b},
$$

where

$$
\mathbf{p}=\left(\begin{array}{c}
p_{1} \\
\vdots \\
p_{n}
\end{array}\right) \in \mathrm{R}^{n}, \mathbf{A}=\left(\begin{array}{cccccc}
\phi & \psi & 0 & \cdots & 0 & \psi \\
\psi & \phi & \psi & 0 & \cdots & 0 \\
0 & \ddots & \ddots & \ddots & \ddots & \vdots \\
\vdots & \ddots & \ddots & \ddots & \ddots & 0 \\
0 & \cdots & 0 & \psi & \phi & \psi \\
\psi & 0 & \cdots & 0 & \psi & \phi
\end{array}\right) \in \mathrm{R}^{n \times n}, \mathbf{b}=\left(\begin{array}{c}
b \\
\vdots \\
b
\end{array}\right) \in \mathrm{R}^{n}
$$

The tridiagonal structure of $\mathbf{A}$ implies that the solution is a symmetric equilibrium $\left\{p_{i}=p, \omega_{i}^{+}=\omega_{i}^{-}=\omega, \Pi_{i}=\Pi\right\}_{i=1,2, \ldots, n}$ where

$$
\begin{gathered}
p_{b s}=\frac{b}{\phi+2 \psi}=c+\frac{1}{n}, \\
\omega_{b s}=\frac{\lambda_{k}^{2}}{(1+\sigma) n}, \text { and } \\
\Pi_{b s}=\frac{1}{n^{2}}\left(1-\frac{\lambda_{k}^{2}}{1+\sigma}\right)-f .
\end{gathered}
$$


As can easily be seen from the above equations, equilibrium profits are lower than in the standard full-information model. Given a market with free entry, long-term equilibrium profits are zero. Thus, there are

$$
n_{b s}=\sqrt{\frac{1}{f}} \sqrt{1-\frac{\lambda_{k}^{2}}{1+\sigma}}<\sqrt{\frac{1}{f}}=n_{0}
$$

firms in the zero-profit market equilibrium. Subscript $b s$ indicates that $n_{b s}$ is the number of firms in a business-stealing equilibrium. Apparently, the opportunity of business stealing through miscounseling uninformed consumers leads to less firms in long-run equilibrium. Dishonest brokers decrease product variety in the market. This implies higher prices in market equilibrium under miscounseling, i.e. $n_{b s}<n_{0}$ leads to $p_{b s}=c+1 / n_{b s}>p_{0}=c+1 / n$. This leads us to

Proposition 1 Firms are in a prisoners' dilemma of business stealing. Gross profits are lower compared to the model under full consumer information. If binding contracts on "fair competition were possible, miscounseling could be abandoned and consumers and firms would be made better off.

As a result, bribery implies that each firm is left with greater market power. We also conclude that the impact of business stealing via intermediary miscounseling on market equilibrium is lower if brokers' markups for miscounseling are higher $(\sigma \uparrow)$ or if consumers' search cost are lower $\left(\lambda_{k} \downarrow\right)$.

miscounseling leads, of course, to welfare losses. In the following, we specify total social cost of miscounseling. When the number of firms decreases, equilibrium price and aggregated mismatch cost of consumers increase. Since aggregated demand is normalized to one, social cost of the price increase is

$$
\Delta p=c+\frac{1}{n_{b s}}-\left(c+\frac{1}{n_{0}}\right)=\sqrt{f}(\underbrace{\sqrt{\frac{1+\sigma}{1+\sigma-\lambda_{k}^{2}}}}_{>1}-1)>0
$$

while additional mismatch cost is

$$
\begin{gathered}
\Delta m=2 n_{f} \int_{0}^{\frac{1}{2 n b s}-\omega} x d x+2 n_{b s} \int_{0}^{\frac{1}{2 n_{b s}}+\omega} \frac{1}{2 n_{b s}} x d x-2 n_{0} \int_{0}^{\frac{1}{2 n} 0} x d x, \text { or } \\
\Delta m=\frac{\left(\frac{8 \lambda_{k}^{3}}{(1+\sigma)^{2}}+1\right)}{4 n_{b s}}-\frac{1}{4 n_{0}},
\end{gathered}
$$

which is equal to

$$
\frac{\sqrt{f}}{4}\left(\sqrt{\frac{1+\sigma}{1+\sigma-\lambda_{k}^{2}}}\left(1+\frac{8 \lambda_{k}^{2}}{(1+\sigma)^{2}}\right)-1\right)>0 .
$$

Treating brokers' earnings from miscounseling as transfers, total social costs of business stealing $\left(S C_{b s}\right)$ is

$$
S C_{b s}=\Delta p+\Delta m=\frac{\sqrt{f}}{4}\left(\sqrt{\frac{1+\sigma}{1+\sigma-\lambda_{k}^{2}}}\left(5+\frac{8 \lambda_{k}^{2}}{(1+\sigma)^{2}}\right)-5\right)>0 .
$$

We summarize these findings in

Proposition 2 Total social costs of business stealing are the lower, the higher the brokers' miscounseling markup are, and the lower the consumers'search cost are.

\section{The Role of Side Payments}

In the business-stealing equilibrium, every firm gains $2 \omega$ demand from its adjacent competitors. Yet, in an equal manner, every firm looses $2 \omega$ demand to its adjacent competitors. Hence, one might ask why firms - being worse off than without miscounseling — cannot fight business stealing? Given the business-stealing equilibrium, a firm might envisage to counter intermediary miscounseling through side payments. Under what conditions is this strategy profitable? Brokers would accept side payments if their profits under side payments 
are higher than in the business-stealing equilibrium. How could a side payments equilibrium practically look like? For instance, one can imagine a trade organization or some regulation authority that observes and verifies brokers' behavior and distributes side payments $(s p)$. This kind of regulation authority exists, for instance, in many financial markets where brokers often act as agents on behalf of consumers.

Definition 2 The set $\left\{n^{s p}, p^{s p}, \omega^{s p}\right\}$ describes a symmetric side-payment equilibrium (SS PE) if

1) Firms: Each firm acts as a monopoly on its brand, that is, given the demand for brand $i$ (7) and the side payments $(s p)$ to the brokers, each firm $i$ chooses $p_{i}$ to

$$
\max _{p_{i}} \Pi_{i}\left(P_{i}\right)=\left(p_{i}-c\right) D_{i}\left(P_{i}\right)-s p-f
$$

2) Free entry: Free entry of firms until every firms earns zero profits, $\Pi_{i}=0 \forall i$.

3) Brokers: Each broker $j$ receives side payments in order to counsel consumers in an honest way.

Suppose an anti-miscounseling agreement between a firm and a broker can be made on condition that brokers receive compensatory payments in return for lost profits. Setting $\omega_{i}^{+}=\omega_{i}^{-}=\omega$, follows that the brokers' profits of miscounseling $2 \omega$ consumers in disfavor of a representative firm are

$$
\pi(2 \omega)=\frac{\sigma \omega^{2}}{\lambda_{k}^{2}}
$$

which represents the minimum side payment required to prevent miscounseling. The firm's profits generated by $2 \omega$ demand are

$$
\Pi(2 \omega)=2 \omega(p-c)=\frac{2 \omega}{n} .
$$

Side payments are taken into account if generated profits outweigh the firm's expenses, i.e., if $\Pi(2 \omega) \geq \pi(2 \omega)$. Consequently, an agreement is in force if

$$
\sigma \leq \frac{2 \lambda_{k}^{2}}{\omega n}
$$

Which, using (19), reduces to $\sigma \geq-2$ which is always true for any $\sigma \geq 0$. We summarize this result in

Proposition 3 The business-stealing equilibrium is not stable when firms envisage side payments in order to incentivize brokers to give consumers right advice. Bribing brokers into correctly counseling consumers is a dominant strategy. As a result, the market is free of miscounseling. There are, however, high side payments which increase prices and make consumers worse off compared to the full-information market equilibrium.

Given that $\sigma \geq-2$, all firms fight business stealing through side-payments. Then (28) together with (19) implies the following profit maximization problem

$$
\max _{p_{i}}\left[\left(p_{i}-c\right) D_{i}\left(P_{i}\right)-\frac{\sigma \lambda_{k}^{2}}{(1+\sigma)^{2} n^{2}}-f\right] .
$$

The first-order condition is 


$$
-\frac{2}{t} p_{i}+\frac{1}{2}\left(p_{i-1}+p_{i+1}\right)=-\frac{1+n c}{n} \quad i=1,2, \ldots, n
$$

Solving this system of equations, we obtain a symmetric equilibrium $\Pi_{i}=\Pi$ and $p_{i}=p$, given $i=1,2, \ldots, n$, where

$$
\begin{gathered}
p_{s p}=c+\frac{1}{n}, \\
\Pi_{s p}=\frac{1}{n^{2}}\left(1-\frac{\sigma \lambda_{k}^{2}}{(1+\sigma)^{2}}\right)-f,
\end{gathered}
$$

implying

$$
n_{s p}=\sqrt{\frac{1}{f}} \sqrt{1-\frac{\sigma \lambda_{k}^{2}}{(1+\sigma)^{2}}}<\sqrt{\frac{1}{f}}=n_{0}
$$

as the number of firms in the zero-profit side-payments equilibrium. Again, side-payments reduce the equilibrium number of firms leading to higher prices and additional mismatch cost, i.e., $n_{s p}<n_{0}$ leads to $p_{s p}=c+1 / n_{s p}>c+1 / n_{O}=p_{0}$, even though these are less compared to miscounseling (since all consumers buy their most preferred product variety). Indeed, social cost of the price increase is

$$
\Delta p=\left(c+\frac{1}{n_{s p}}-c-\frac{1}{n_{0}}\right)=\sqrt{f}(\underbrace{\sqrt{\frac{(1+\sigma)^{2}}{(1+\sigma)^{2}-\sigma \lambda_{k}^{2}}}}_{>1}-1)>0,
$$

and additional mismatch cost is

$$
\Delta m=2 n_{s p} \int_{0}^{\frac{1}{2 n_{s p}}} x d x-2 n_{0} \int_{0}^{\frac{1}{2 n_{0}}} x d x,
$$

which is equal to

$$
\frac{1}{4}\left(\frac{1}{n_{s p}}-\frac{1}{n_{0}}\right)=\frac{\sqrt{f}}{4}\left(\sqrt{\frac{(1+\sigma)^{2}}{(1+\sigma)^{2}-\sigma \lambda_{k}^{2}}}-1\right)>0 .
$$

Therefore, total social cost generated by side-payments is

$$
S C_{s p}=\frac{5 \sqrt{f}}{4}\left(\sqrt{\frac{(1+\sigma)^{2}}{(1+\sigma)^{2}-\sigma \lambda_{k}^{2}}}-1\right)>0 .
$$

This leads us to the following

Proposition 4 Side payments are welfare improving compared to miscounseling. Social cost under business stealing and miscounseling is always higher than social cost under side-payments because all consumers buy their most preferred product variety.

To show that social costs under side-payments are lower, we consider the difference in social costs

$$
S C_{b s}-S C_{s p}=\frac{5 \sqrt{f}}{4}\left(\sqrt{\frac{1+\sigma}{1+\sigma-\lambda_{k}^{2}}}\left(1+\frac{8 \lambda_{k}^{2}}{5(1+\sigma)^{2}}\right)-\sqrt{\frac{(1+\sigma)^{2}}{(1+\sigma)^{2}-\sigma \lambda_{k}^{2}}}\right)
$$




$$
\geq \frac{5 \sqrt{f}}{4}\left(\sqrt{\frac{1+\sigma}{1+\sigma-\lambda_{k}^{2}}}-\sqrt{\frac{(1+\sigma)^{2}}{(1+\sigma)^{2}-\sigma \lambda_{k}^{2}}}\right)
$$

which is equivalent to show that

$$
\sqrt{\frac{1+\sigma}{1+\sigma-\lambda_{k}^{2}}} \geq \sqrt{\frac{(1+\sigma)^{2}}{(1+\sigma)^{2}-\sigma \lambda_{k}^{2}}} \Leftrightarrow(1+\sigma)^{2}-\sigma \lambda_{k}^{2} \geq(1+\sigma)\left(1+\sigma-\lambda_{k}^{2}\right) \Leftrightarrow \lambda_{k}^{2} \geq 0 .
$$

Since $\lambda_{k}^{2}$ is always positive, the above inequality always holds.

\section{The Conduct of the Brokers}

In the preceding sections, the brokers' miscounseling markup has been some variable parameter allowing us to conclude that externalities of business stealing are lower when brokers' markup is higher. Moreover, we found that business stealing becomes unprofitable under side payments. Certainly, when business stealing is more expensive, such kind of unfair competition inducing externalities on consumers becomes less attractive. To complete the analysis, using broker profit maximization, we will determine the actual markup $\sigma$. Since the business stealing market is monopolistically competitive, we find that brokers earn monopoly profits. From (28), monopoly profit of a representative broker $j$ is

$$
\pi_{j}\left(\sigma_{j}\right)=\frac{n \sigma_{j} \omega_{b s}^{2}}{m \lambda_{k}^{2}} .
$$

Substituting for (19) gives the following profit maximization problem

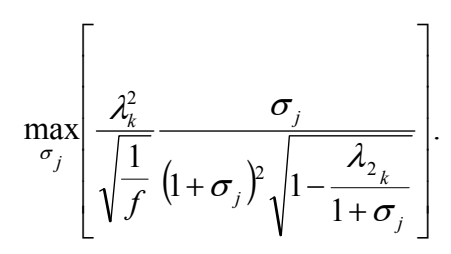

This function has a unique maximum at

$$
\sigma^{*}=\frac{1}{4}\left(\lambda_{k}^{2}+\sqrt{\lambda_{k}^{4}-16 \lambda_{k}^{2}+16}\right)
$$

Thus, $\sigma^{*} \in[0,1] \forall \lambda \in(0,1)$. Finally, the number of firms in market equilibrium under side payments is then given by

$$
n^{*}=\sqrt{\frac{1}{f}} \sqrt{1-\frac{\frac{1}{4}\left(\lambda_{k}^{2}+\sqrt{\lambda_{k}^{4}-16 \lambda_{k}^{2}+16}\right) \lambda_{k}^{2}}{\left(\frac{1}{4}\left(\lambda_{k}^{2}+\sqrt{\lambda_{k}^{4}-16 \lambda_{k}^{2}+16}\right)+1\right)^{2}}}<\sqrt{\frac{1}{f}}=n_{0} .
$$

Equilibrium prices and profits are given by (33) and (34) together with $n^{*}$.

In summary, we have found that a long-run market equilibrium — given a market where bribable brokers might miscounsel consumers against some fee and firms might counter business stealing through side payments to brokers - will probably be characterized by the following properties:

1. Every consumer purchases the product that actually matches his preferences.

2. There is no miscounseling in equilibrium but every firm makes side payments to brokers to counter them from business stealing.

3. Prices are higher than in a standard full-information equilibrium since firms include side payments to brokers in their prices.

4. Due to side payments, equilibrium gross profits are lower and thus the number of firms in market 
equilibrium is also lower than in the standard full-information equilibrium.

5. Brokers make high profits from side payments.

\section{Summary}

In this paper, we have analyzed the impact of fraudulent independent experts on market performance and efficiency in a Salop-market of monopolistic competition. In such a market, experts may want to give the wrong advice to their customers in order to receive collusive business stealing payments for doing so by firms, thereby preventing consumers from consuming a better product variety offered by other firms. This argument applies to various industries such as repair markets, health care markets, and financial services markets where consumers are usually uninformed about which of the offered product varieties best fits their individual needs.

Our analysis provides several interesting insights. First, fraudulent independent experts imply fewer firms in market equilibrium, which is associated with greater market power and higher prices compared to the standard Salop market equilibrium under full consumer information. Second, as a consequence, bribable independent experts entail welfare losses for both consumers and firms. More generally, due to the presence of fraudulent experts, the parties are caught in a prisoners' dilemma: firms and consumers would be better off without fraudulent experts. We also show that an equilibrium without miscounseling may require side payments from the firms to the brokers. Therefore, rigorous regulation of the relationship between firms and intermediaries as well as severe fines in case of detection of bribery seem necessary in order to make these markets operate more efficiently.

\section{Acknowledgements}

We would like to dedicate this article to Johann Buhné (†) who made a valuable contribution.

\section{References}

Allen, F., \& Santomero, A. (1997). The theory of financial intermediation. Journal of Banking \& Finance, 21, 1461-1485. http://dx.doi.org/10.1016/S0378-4266(97)00032-0

Biglaiser, G. (1993). Middlemen as experts. The RAND Journal of Economics, 24, 212-223. http://www.jstor.org/stable/2555758

Campbell, T., \& Kracaw, W. (1982). Information production, market signalling, and the theory of financial intermediation: A reply. The Journal of Finance, 37, 1097-1099. http://www.jstor.org/stable/2327771

Chan, Y. S. (1983). On the positive role of financial intermediation in allocation of venture capital in a market with imperfect information. The Journal of Finance, 38, 1543-1568. http://dx.doi.org/10.1111/j.1540-6261.1983.tb03840.x

Cosimano, T. (1996). Intermediation. Economica, 63, 131-143. http://www.jstor.org/stable/2554638

Cummins, D., \& Doherty, N. (2006). The economics of insurance intermediaries. Journal of Risk \& Insurance, 73, 359-396. http://dx.doi.org/10.1111/j.1539-6975.2006.00180.x

Diamond, D. (1984). Financial intermediation and delegated monitoring. The Review of Economic Studies, 51, 393-414. http://dx.doi.org/10.2307/2297430

Dulleck, U., \& Kerschbamer, R. (2006). On doctors, mechanics, and computer specialists: The economics of credence goods. Journal of Economic Literature, 44, 5-42. http://www.jstor.org/stable/10.2307/30032295

Fitzpatrick, S. (2006). The small laws: Eliot spitzer and the way to insurance market reform. Fordham Law Review, 74, 3041-3071.

Gravelle, H. (1994). Remunerating information providers: Commissions versus fees in life insurance. The Journal of Risk and Insurance, 61, 425-457. Retrieved from http://www.jstor.org/stable/10.2307/253569

Hoffmann, F., \& Inderst, R. (2011). Pre-sale information. Journal of Economic Theory, 146, 2333-2355. http://dx.doi.org/10.1016/j.jet.2011.10.009

Inderst, R. (2011). Consumer protection and the role of advice in the market for retail financial services. Journal of Institutional and Theoretical Economics, 167, 4-21. http://dx.doi.org/10.1628/093245611794656417

Inderst, R., \& Ottaviani, M. (2009). Misselling through agents. The American Economic Review, 99, 883-908. http://dx.doi.org/10.1257/aer.99.3.883

Inderst, R., \& Ottaviani, M. (2012). Competition through commissions and kickbacks. American Economic Review, 102(2), 780-809. http://dx.doi.org/10.1257/aer.102.2.780 
Inderst, R., \& Ottaviani, M. (2011). Consumer protection in markets with advice. Competition Policy International, 6, 47-64.

Leland, H., \& Pyle, D. (1977). Informational asymmetries, financial structure, and financial intermediation. The Journal of Finance, 32, 371-387. http://dx.doi.org/10.1111/j.1540-6261.1977.tb03277.x

Polo, M. (1991). Hotelling duopoly with uninformed consumers. The Journal of Industrial Economics, 39, 701-715. Retrieved from http://www.jstor.org/stable/2098672

Posey, L., \& Tennyson, S. (1998). The coexistence of distribution systems under price search: Theory and some evidence from insurance. Journal of Economic Behavior \& Organization, 35, 95-115. http://dx.doi.org/10.1016/S0167-2681(97)00100-5

Posey, L., \& Yavas, A. (1995). A search model of marketing systems in property-liability insurance. The Journal of Risk and Insurance, 62, 666-689. http://www.jstor.org/stable/253590

Rubinstein, A., \& Wolinsky, A. (1987). Middlemen. The Quarterly Journal of Economics, 102, 581-594. http://dx.doi.org/10.2307/1884218

Salop, S., (1979). Monopolistic competition with outside goods. The Bell Journalof Economics, 10, 141-156. http://www.jstor.org/stable/3003323

Seog, H. (1999). The coexistence of distribution systems when consumers are not informed. The Geneva Papers on Risk and Insurance Theory, 24, 173-192. http://dx.doi.org/10.1023/A:1008741627883

Spitzer, E. (2004). Investigation reveals widespread corruption in insurance industry. Press Release: Office of New York State Attorney General Eliot Spitzer. Retrieved from http://www.oag.state.ny.us

Williamson, S. (1987). Costly monitoring, loan contracts, and equilibrium credit rationing. The Quarterly Journal of Economics, 102, 135-145. http://dx.doi.org/10.1016/0304-3932(86)90074-7

\section{Notes}

Note 1. The "principle of insufficient reason" was first expressed by Jacob Bernoulli. It states that if an agent is ignorant of the ways an event might occur (and therefore has no reason to believe that one way will occur rather than another), the event will occur equally likely.

Note 2. The fee covers the brokers' cost. In insurance markets, for instance, a risk analysis is usually expensive since it requires expertise not only in finance, but also in actuarial science, law, and engineering. For details, see Cummins and Doherty (2006), p. 392.

Note 3. Firms could offer location-specific "bids" to brokers for miscounseling. We assume, however, that such location-specific "bids" are too costly to implement. 